OPEN ACCESS

Edited by:

David L. Swanson,

University of South Dakota,

United States

Reviewed by:

Ben Smit,

Rhodes University, South Africa Nathan Wolf,

Alaska Pacific University, United States

*Correspondence: Pablo Sabat psabat@uchile.cl

Specialty section:

This article was submitted to Ecophysiology,

a section of the journal

Frontiers in Ecology and Evolution

Received: 30 August 2021

Accepted: 15 October 2021

Published: 12 November 2021

Citation:

Navarrete L, Bozinovic $F$

Peña-Villalobos I,

Contreras-Ramos $C$,

Sanchez-Hernandez JC,

Newsome SD, Nespolo RF and

Sabat $P$ (2021) Integrative

Physiological Responses to Acute

Dehydration in the Rufous-Collared

Sparrow: Metabolic, Enzymatic,

and Oxidative Traits.

Front. Ecol. Evol. 9:767280.

doi: 10.3389/fevo.2021.767280

\section{Integrative Physiological Responses to Acute Dehydration in the Rufous-Collared Sparrow: Metabolic, Enzymatic, and Oxidative Traits}

\author{
Lucas Navarrete ${ }^{1,2}$, Francisco Bozinovic ${ }^{2}$, Isaac Peña-Villalobos ${ }^{1,3}$, \\ Carolina Contreras-Ramos ${ }^{1,2,4}$, Juan C. Sanchez-Hernandez ${ }^{5}$, Seth D. Newsome ${ }^{6}$, \\ Roberto F. Nespolo ${ }^{2,7,8}$ and Pablo Sabat ${ }^{1,2 *}$
}

\begin{abstract}
' Departamento de Ciencias Ecológicas, Facultad de Ciencias, Universidad de Chile, Santiago, Chile, ${ }^{2}$ Center of Applied Ecology and Sustainability (CAPES), Pontificia Universidad Católica de Chile, Santiago, Chile, ${ }^{3}$ Laboratorio de Células Troncales y Biología del Desarrollo, Departamento de Biología, Facultad de Ciencias, Universidad de Chile, Santiago, Chile, ${ }^{4}$ Facultad de Medicina Veterinaria y Agronomía, Universidad de Las Américas, Santiago, Chile, ${ }^{5}$ Laboratory of Ecotoxicology, University of Castilla-La Mancha, Toledo, Spain, ${ }^{6}$ Department of Biology, University of New Mexico, Albuquerque, NM, United States, ${ }^{7}$ Instituto de Ciencias Ambientales y Evolutivas, Universidad Austral de Chile, Valdivia, Chile, ${ }^{8}$ Millennium Institute for Integrative Biology, Santiago, Chile
\end{abstract}

Predictions indicate that birds worldwide will be affected by global warming and extreme climatic events which is especially relevant for passerines because the diurnal habits, small body size, and high mass-adjusted metabolic rates of this group make it particularly susceptible to increases in temperature and aridity. Some bird species respond to conditions that stress osmoregulation by increasing their rates of energy expenditure, nevertheless, the effect of dehydration on metabolic rates in birds has produced contrasting results. It also remains unknown whether hydration state may cause shifts in tissue-specific metabolic rates or modify tissue oxidative status. We used the rufous-collared sparrow (Zonotrichia capensis), to experimentally test the effect of dehydration on metabolic enzymes in erythrocytes, tissue oxidative status, basal metabolic rate (BMR), and total evaporative water loss. We found a significant increase in mass-adjusted BMR in water restricted (WR) birds compared to control birds (CT). Activity of cytochrome-c-oxidase (COX) in red blood cells (RBCs) was also significantly higher in the WR group relative to the CT group and this activity was positively correlated with mass-adjusted BMR. We found a moderate effect of water restriction on membrane damage of skeletal muscle. In a second set of individuals subjected to the same experimental conditions, lean mass and total water were tightly correlated and decreased by 10 and 12\%, respectively, in birds in the WR group relative to the CT group. Decreases in total water and lean mass leads to an increase in massadjusted BMR in WR $Z$. capensis, suggesting that birds may simultaneously increase protein catabolism and production of metabolic water through oxidation. The significant positive relationship between $\mathrm{BMR}$ and $\mathrm{COX}$ in RBCs is a finding that requires additional research to determine whether erythrocyte metabolism is affected by dehydration per se and or it more generally reflects rates of energy expenditure in birds.

Keywords: basal metabolic rate (BMR), body composition, metabolic enzymes, oxidative stress, birds, dehydration 


\section{INTRODUCTION}

Increased frequency in droughts and heat waves are predicted to have a strong influence on plant and animal phenology, behavior, and physiology (Walther et al., 2002; Albright et al., 2017). Although predictions indicate all birds worldwide will be affected by global warming and climatic extreme events, species that live in subtropical and temperate deserts will be disproportionately impacted by climate change because the magnitude and perhaps rate of change in these regions will likely be larger and faster than in other biomes (McKechnie and Wolf, 2010; Albright et al., 2017; Iknayan and Beissinger, 2018). This is especially relevant for passerines because the general behavioral (e.g., diurnal), evolutionary (e.g., small body size), and physiological (e.g., high mass-specific metabolic rates, dissipate heat via panting) traits of this group make it particularly susceptible to increases in temperature and aridity (Yom-Tov, 2001; Gardner et al., 2011; Albright et al., 2017). To better assess how rapid environmental changes threatens species' persistence, phenomenological data should be combined with laboratory experiments to identify the mechanisms that control how animals respond to environmental conditions (Khaliq et al., 2014).

Maintaining osmotic balance is a challenge when birds are feeding on salty food or living in arid habitats that contain scarce freshwater (Sabat and Martinez del Rio, 2002; Sabat et al., 2009; Smit and McKechnie, 2015). Avian water balance is a function of the interplay between water availability in the environment, the physiological and behavioral mechanisms birds use to reduce water losses, and the production of metabolic water that is directly linked to metabolic rate (Gerson and Guglielmo, 2011; Albright et al., 2017; Sabat et al., 2021). Some bird species respond to environmental conditions that stress osmoregulation by increasing their rates of energy expenditure, including basal metabolic rate (BMR). This response has been associated with an increase in hyperosmotic urine excretion, which in turn comprises both the energy cost of osmoregulation per se (McWhorter et al., 2004) and the long-term effect of increasing the mass and metabolic intensity of tissues such as the kidneys and heart (Daan et al., 1990; Gutiérrez et al., 2011; Peña-Villalobos et al., 2013; Sabat et al., 2017). Nevertheless, the effect of dehydration on metabolic rates in birds has produced contrasting results (Cade et al., 1965; Gerson and Guglielmo, 2011).

Another potential cost of dehydration could be the oxidative stress that results from maintaining high metabolic rates. Mitochondria are the principal source of cellular reactive oxygen species (ROS) associated with the production of superoxide anions as byproducts of the electron transport chain and other redox reactions (Srinivasan and Avadhani, 2012). Several studies have reported that increases in metabolic rate results in higher production of ROS, which consequently stimulates energetically intensive antioxidant defense (Commoner et al., 1954; Cohen et al., 2008; Tumminello and Fuller-Espie, 2013). Moreover, some studies have shown that osmotic stress affects several physiological traits in birds, including shifts in tissue-specific metabolic rates and oxidative status (Tieleman et al., 2003; TapiaMonsalve et al., 2018; Sabat et al., 2019). In support of this mechanism, a recent study revealed that baseline corticosterone levels were higher in water-deprived house sparrows (Brischoux et al., 2020), and glucocorticoid has been shown to disturb cellular oxidative homeostasis (Costantini et al., 2011; Queisser et al., 2011). Furthermore, recent evidence indicates that dehydration induced by high environmental temperatures influences cellular metabolism in mammals, ultimately yielding an elevated antioxidant response and/or oxidative damage (Jacobs et al., 2020). It remains unknown whether hydration state and changes in osmotic conditions may cause oxidative damage in birds. We predicted that a potential additional cost of dehydration is the increased production of ROS, which leads to cumulative damage of biomolecules, Costantini et al. (2010).

Cells can shrink in response to increases in blood plasma osmolality by hydric stress, and erythrocytes must maintain their volume by means of energy intensive ion regulation (Hoffmann et al., 2009; Gerson and Guglielmo, 2011). Birds have functional mitochondria in their red blood cells (RBCs) containing specific enzymes that provide immediate energy for ion-transporting proteins (Moritz et al., 1997; Stier et al., 2013). Recent studies have documented the existence of significant inter-individual variation in the energy expenditure rates of erythrocyte mitochondria in birds. Specifically, variation in mitochondrial metabolism is associated with the activity of the metabolic enzymes Citrate Synthase (CS) and Cytochrome C Oxidase (COX) in skeletal muscle (Stier et al., 2015, 2017). These two enzymes are responsible for energy (ATP) production such that the activity of these enzymes is correlated with whole-body energy consumption rates in birds (Peña-Villalobos et al., 2014; Gutiérrez et al., 2019). Thus, it is possible that the metabolism of the mitochondria, through the expression of enzymes involved in the expenditure of energy at the tissue and peripheral level, is correlated with physiological modifications that occur in birds subjected to water stress.

Here we integrated blood-based measurement of energy metabolism (e.g., CS and COX) with oxidative status (e.g., lipid peroxidation and glutathione balance) and BMR to examine the osmoregulatory adjustments to dehydration in captive rufous-collared sparrows (Zonotrichia capensis), a common passerine bird inhabiting southern South America. Specifically, we hypothesize that birds exposed to water restriction for 2 weeks will show higher plasma and urine osmolality, activity of the mitochondrial enzymes, and metabolic rates than hydrated (control) birds. We also predict that water restricted (WR) birds should exhibit a higher ratio of oxidized (GSSG) to reduced (GSH) glutathione; higher lipid peroxidation (MDA concentration) as a measurement of oxidative damage, higher of hydrogen peroxides $\left(\mathrm{H}_{2} \mathrm{O}_{2}\right)$ concentrations, and enhanced total antioxidant capacity (TAC).

\section{MATERIALS AND METHODS}

\section{Laboratory Acclimation}

A total of 18 Z. capensis (Passeriformes: Emberizidae) individuals were captured in November 2018. Captive birds were held for 2 weeks at a constant temperature of $25 \pm 2^{\circ} \mathrm{C}$ within 
their thermoneutral zone (TNZ; Sabat et al., 2019) and housed individually in plastic-mesh cages $(35 \mathrm{~cm} \times 35 \mathrm{~cm} \times 35 \mathrm{~cm})$ under a 12L:12D photoperiod. After capture, each bird was assigned to one of two treatments: a control (CT) group was maintained with water and seeds ad libitum and a WR group with seeds ad libitum that during the first week were allowed to drink fresh water every $24 \mathrm{~h}$, and the second week every $48 \mathrm{~h}$. Individuals were weighed with a scale $( \pm 0.001 \mathrm{~g})$ at the beginning and end of each week of treatment. Birds were captured with permits issued by Servicio Agricola Ganadero (No. 10192/2019). All protocols were approved by the institutional Animal Care Committee of the University of Chile where experiments were performed.

\section{Basal Metabolic Rate and Total Evaporative Water Loss}

Immediately after each treatment, we measured BMR (mL $\mathrm{O}_{2} \mathrm{~h}^{-1}$ ) and total evaporative water loss (TEWL) in postabsorptive (fasted for 4-h) resting birds during the night between 21:00 and 07:00 h using standard flow-through respirometry methods. Respirometry measurements were performed on three birds per night and staggered such that the beginning of the water restriction experiments started sequentially. Oxygen consumption was measured using three computerized openflow respirometry systems (two FMS, one FOXBOX, Sable Systems, Henderson, NV, United States) calibrated with a known mix of oxygen (20\%) and nitrogen (80\%) that were certified by chromatography (INDURA, Chile) and then placed in a controlled temperature cabinet (Sable Systems, Henderson, Nevada) at a constant ambient temperature of $30 \pm 0.5^{\circ} \mathrm{C}$ that is within the TNZ for this species (Sabat et al., 2019). The metabolic chamber received dried air at $500 \mathrm{~mL} \mathrm{~min}{ }^{-1}$ through Bev-A-Line tubing (Thermoplastic Processes Inc) from a mass flow controller. The excurrent air passed through a hygrometer that recorded vapor pressure $(\mathrm{kPa})$ and then through columns of Baralime to absorb $\mathrm{CO}_{2}$ before passing through the $\mathrm{O}_{2}$-analyzer. Because $\mathrm{CO}_{2}$ was scrubbed before entering the $\mathrm{O}_{2}$ analyzer, oxygen consumption was calculated as (Withers, 1977): $\left.\mathrm{V} \cdot \mathrm{O} 2=\left[\mathrm{FR} \times 60 \times\left(\mathrm{Fi} \mathrm{O} 2-\mathrm{Fe} \mathrm{O} \mathrm{O}_{2}\right)\right] /(1-\mathrm{Fi} \mathrm{O} 2)\right]$, where FR is the flow rate in $\mathrm{mL} / \mathrm{min}, \mathrm{Fi}$ and $\mathrm{Fe}$ are the fractional concentrations of $\mathrm{O}_{2}$ entering and leaving the metabolic chamber, respectively. TEWL was calculated as TEWL $=\left[\left(\mathrm{Ve} \rho_{\text {out }}-\mathrm{Vi} \rho_{\text {in }}\right)\right]$ where TEWL is in $\mathrm{mg} / \mathrm{mL}$. $\rho$ in and $\rho$ out are the absolute humidity in $\mathrm{kg} / \mathrm{m}^{3}$ of the inlet air and the outlet air, respectively, Ve is the flow rate of the air entering the chamber as given by the mass flow controller equipped with the FMS and FOXBOX $\left(500 \mathrm{~mL} \mathrm{~min}^{-1}\right.$ ) and $\mathrm{Ve}$ is the flow of exiting air. $\mathrm{Ve}$ was calculated following (Tieleman et al., 2003) as $\mathrm{Ve}=\mathrm{Vi}-\left[\mathrm{V} \cdot \mathrm{O}_{2}\right.$ $(1-\mathrm{RQ})]+\mathrm{VH}_{2} \mathrm{O} \mathrm{Vi}$, and $\mathrm{V} \cdot \mathrm{O}_{2}\left(\mathrm{~mL} \mathrm{~min}^{-1}\right)$ are known. We used a respiratory quotient (RQ) of 0.71 , which assumes that fasting sparrows rely mainly on stored lipids for metabolism (King and Farner, 1961; Walsberg and Wolf, 1995). Absolute humidity was calculated as $\rho=\mathrm{P} /(\mathrm{T} \times \mathrm{Rw})$, where $\mathrm{P}$ is water vapor pressure of the air in Pascal, $T$ is the temperature of the dew-point hygrometer in Kelvin and Rw is the gas constant for water vapor [461.5 J/kg $\times$ Kelvin, (Lide, 2001)]. The $\rho_{\text {in }}$ was determined using the average value of the vapor pressure of the air entering the empty chamber during the 15 -min baseline period before and after each experiment. Body mass was measured before the metabolic measurements using an electronic balance $( \pm 0.1 \mathrm{~g})$ and cloacal body temperature $(\mathrm{Tb})$ was recorded with a thin Cole- Palmer copper-constantan thermocouple attached to a Digisense thermometer (Model 92800-15) within a minute after the birds were removed from metabolic chamber. We found that all animals were euthermic after the metabolic trials $\left(\mathrm{Tb}>40^{\circ} \mathrm{C}\right)$. Data readings were performed through EXPEDATA software (Sable Systems, International, NV, United States). To estimate basal metabolic rate and TEWL, we averaged $\mathrm{O}_{2}$ concentrations and water vapor pressures of the excurrent air stream over a 20 min period after steady state was reached, which typically occurs after $3 \mathrm{~h}$ in $Z$. capensis (Maldonado et al., 2009). We estimated the metabolic water production (MWP) of sparrows using the equivalence of $0.567 \mathrm{~mL} \mathrm{H}_{2} \mathrm{O}$ per liter $\mathrm{O}_{2}$ consumed (Schmidt-Nielsen, 1997). We calculated the ratio between MWP and water losses (MWP/TEWL) for the $20 \mathrm{~min}$ period in which the steady state was reached.

\section{Blood and Urine Osmolality}

Blood (50-100 $\mu \mathrm{L})$ was collected in the morning (09:00-11:00 h) prior to physiological measurements from the humeral vein using hematocrit tubes with anticoagulant (heparine or EDTA). Blood samples were centrifuged at $10,000 \mathrm{~g}$ for $5 \mathrm{~min}$ to separate plasma from RBCs, and both fractions were frozen at $-80^{\circ} \mathrm{C}$ until analysis. Ureteral urine was obtained by inserting a small closedended cannula into the bird's cloaca, which was centrifuged, and the supernatant was collected for osmometry analysis (Wescor 5130B). After metabolic measurements, birds were sacrificed by $\mathrm{CO}_{2}$ exposure, weighed, and the organs were removed and frozen at $-80^{\circ} \mathrm{C}$.

\section{Metabolic Enzymes}

Blood pellets consisting of the cellular fraction comprised mostly of RBCs was thawed and transferred to a Falcon tube, weighed in an analytic balance $( \pm 0.0001)$, and homogenized on ice (1:4 $\mathrm{w} / \mathrm{v}$ ) in phosphate buffer $0.1 \mathrm{M}$ supplemented with $2 \mathrm{mM}$ EDTA ( $\mathrm{pH}$ 7.3). To obtain similar masses of RBC isolates across samples, the weight of a given RBC pellet was corrected by the value of the mean hematocrit of all samples (i.e., $w \times$ [sample hematocrit/mean hematocrit]). The samples were then sonicated using a 130 Watt Ultrasonic Processor (VCX 130) on ice 14 times in 20-s cycles and 10-s interval between cycles. Homogenates were then centrifuged at $14,000 \mathrm{rpm}$ for $15 \mathrm{~min}$ at $4^{\circ} \mathrm{C}$ to obtain a post mitochondrial fraction. The supernatant was transferred into a new tube to avoid transferring the upper lipid layer present in the homogenate. Protein concentrations were determined using the method by Bradford (1976) with bovine serum albumin as the standard. We measured the activity of two mitochondrial enzymes: COX (E.C. 1.9.3.1) and CS (E.C. 4.1.3.7). COX activity was quantified using a microplate spectrophotometric method in which enzyme activity was measured in a reaction mixture containing $10 \mathrm{mM}$ Tris- $\mathrm{HCl}$ ( $\mathrm{pH} \mathrm{7),} 120 \mathrm{mM} \mathrm{KCl,} 250 \mathrm{mM}$ sucrose, and cytochrome $\mathrm{c}$ reduced with dithiothreitol in a final volume of $0.2 \mathrm{~mL}$. The decrease in extinction at $550 \mathrm{~nm}$ 
was monitored in a Thermo Scientific Multiskan GO UV/VIS spectrophotometer at $25^{\circ} \mathrm{C}$. COX activity was calculated using an extinction coefficient of $21.84 \mathrm{mM}^{-1} \mathrm{~cm}^{-1}$ at $550 \mathrm{~nm}$. To quantify CS, the enzyme assay medium contained $10 \mathrm{mM}$ Tris$\mathrm{HCl}$ (pH 8.0), $10 \mathrm{mM}$ 5,5'dithiobis- (2 nitrobenzoic acid), $30 \mathrm{mM}$ acetyl Coenzyme A (acetyl CoA) and $10 \mathrm{mM}$ oxaloacetic acid (OAA) in a final volume of $0.2 \mathrm{~mL}$; these reagents were omitted in controls. CS catalyzes the reaction between acetyl CoA and OAA to form citric acid. The increase in extinction at $412 \mathrm{~nm}$ was measured in a Thermo Scientific Multiskan GO at $25^{\circ} \mathrm{C}$. CS activity was calculated using an extinction coefficient of $13.6 \mathrm{mM}^{-1} \mathrm{~cm}^{-1}$ at $412 \mathrm{~nm}$ (Peña-Villalobos et al., 2014).

\section{Oxidative Stress}

Tissues were thawed and processed following the specific procedures for each analytic protocol (see below). Oxidative stress was evaluated by measuring the concentration of reduced (GSH) and oxidized (GSSG) glutathione in pectoralis and liver. Lipid peroxidation (TBARS) was measured in plasma, liver, heart, pectoral, and RBCs. Hydrogen peroxides $\left(\mathrm{H}_{2} \mathrm{O}_{2}\right)$ were measured in plasma, liver, heart and pectoralis. Finally, we measured TAC in plasma, heart and pectoralis.

Concentration of reduced (GSH) and oxidized (GSSG) glutathione was measured in the acid supernatants, which were obtained by treatment of the post-mitochondrial fraction $(200 \mu \mathrm{L})$ with $200 \mu \mathrm{L}$ of cold $0.6 \%(\mathrm{w} / \mathrm{v})$ sulfosalicylic acid, and centrifuged $\left(10.000 \times g, 5 \mathrm{~min}, 4^{\circ} \mathrm{C}\right)$ after keeping the samples for $5 \mathrm{~min}$ on ice. Determination of GSH and GSSG concentrations followed the colorimetric method by Rahman et al. (2006), adapted to microplate format. Lipid peroxidation was measured in plasma, liver, heart, pectoral, and RBCs (EF) with a commercial kit Oxiselect, STA-330 Cell Biolabs; (Gutiérrez et al., 2019). The assay evaluates the joint between adduct. Absorbance was measured in a Thermo Scientific Multiskan GO UV/VIS spectrophotometer at $25^{\circ} \mathrm{C}$. We measured hydrogen peroxides $\left(\mathrm{H}_{2} \mathrm{O}_{2}\right)$ in plasma as a measure of the pro-oxidant status (Costantini, 2014) using a commercial kit (MAK311, Sigma Aldrich). The assay evaluated colorimetrically the oxidation of $\mathrm{Fe}^{+2}$ to $\mathrm{Fe}^{+3}$ by peroxides present in the sample at $585 \mathrm{~nm}$. We also measured antioxidant capacity with the adjustment for microtiter plate (Ribeiro et al., 2011). In brief, the assay measures the reduction of $\mathrm{Cu}$ (II)-neocuproine complex to $\mathrm{Cu}(\mathrm{I})$ neocuproine complex by antioxidants present in the sample, the assay is measured spectrophotometrically at $450 \mathrm{~nm}$, and the sample value is compared with a known Trolox standard curve.

\section{Quantitative Magnetic Resonance}

To estimate the effect of dehydration on body composition, we repeated the experiment of water restriction on a second set of $Z$. capensis $(n=11)$ captured from the same locality and subject to the same experimental conditions. For logistical reasons, we could not analyze the body composition of birds in the initial experiment. At the end of this second acclimation experiment, on the night after the last dehydration period (i.e., Day 14), birds were transported to the Universidad Austral de Chile in Valdivia $(\sim 850 \mathrm{Km}$ from Santiago, $10 \mathrm{~h}$ of travel) and inserted into a EchoMRI 500 (Houston, TX, United States) quantitative magnetic resonance (QMR) instrument to directly measure grams of lean mass, fat mass, and total, and free body water. This instrument has been validated in wild animals (Riley et al., 2016; Kraft et al., 2019; Eastick et al., 2020) and has been specifically used to measure changes in lean and fat mass during migration in birds (Guglielmo et al., 2011; Kelsey and Bairlein, 2019). For each measurement, the animal was placed in an acrylic cylinder ( $5 \mathrm{~cm}$ diameter, $60 \mathrm{~cm}$ long) and immobilized by a Velcro-secured plunger placed inside the cylinder. The cylinder was then placed into the magnetic resonance module, which was programmed for three scans per animal achieved in $\sim 1.5 \mathrm{~min}$. If the coefficient of variation of these scans exceeded $6 \%$, usually due to movement of the animal within the probe, the measurement was discarded and repeated. We calibrated the QMR daily before every batch of measurements according to manufacturer's recommendation by using a sample of canola oil of known mass. We calculated a hydration index for each individual birds as: total water - free water/lean mass.

\section{Statistical Analysis}

We used Repeated Measures Analysis of Variance (RM-ANOVA) and a posteriori Fisher test to assess differences in body mass between the experimental treatments. The same procedure was used for the second experimental group of birds used to estimate body composition. We evaluated the effect of water availability on BMR, TEWL, organ masses, biomarkers of oxidative stress, and fluid concentrations using a general linear model (GLM) with final body mass as a covariate and hydration state as fixed factors. We initially included a treatment by body mass interaction, but this interaction was not significant and removed from the linear model. We then tested the effect of the covariates body mass and treatment again, and when the covariate was nonsignificant, we removed this term from the model. To estimate the extent to which metabolic enzyme activity is associated with body mass and metabolic rate, we ran a multiple linear regression using whole BMR as the response variable and enzyme activities and body mass as predictors. Finally, we calculated and plotted the residuals of the linear regression between body mass and enzyme activities. All statistical analyses were performed using STATISTICA ${ }^{\otimes}$ statistical package for Windows. For simplicity, here we only present results from analyses using the covariate when the GLM revealed a significant effect of body mass. Detailed results of the effects of body mass and the interaction between body mass and treatment are reported in Supplementary Table 1.

\section{RESULTS}

\section{Body and Organ Mass}

We found a significant effect of experimental time on body mass [RM ANOVA, $F(3,48)=47.48 ; p<0.01$ ], with a steeper decline in body mass over time in the WR group (Figure 1) such that by day 7 the two treatments significantly differed from one another $\left[F_{(1,16)}=25.82 ; p<0.01\right.$, Figure 1]. We also found an interaction between time and treatment on body mass $\left[F_{(3,48)}=12.05\right.$; $p<0.01]$, with the WR group being the most affected and losing up to $17.7 \%$ of initial mass on average, while the CT group only 


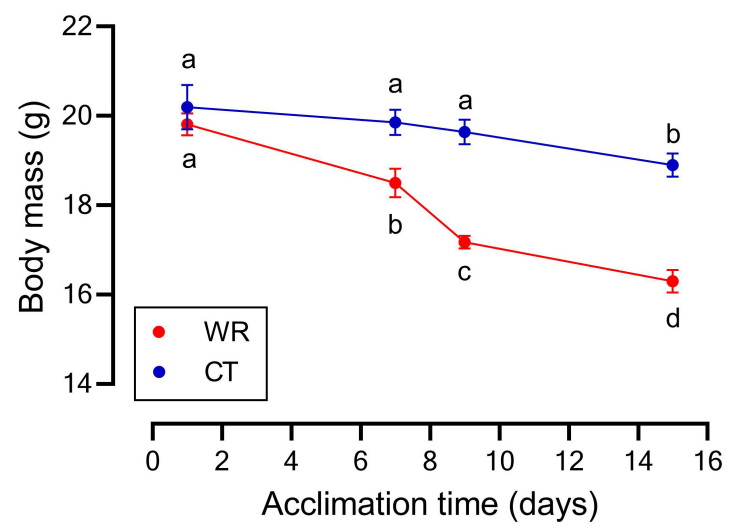

FIGURE 1 | Mean body mass of $Z$. capensis acclimated to control (CT, $n=9$ ) and water restriction (WR, $n=9$ ) conditions; error bars represent standard deviation. Letters denote significant differences between each treatment at specific time points with a repeated measures ANOVA and posteriori Tukey HSD test.

TABLE 1 | Organ masses (means and LSM \pm standard error) of Z. capensis acclimated to hydrated (control) and water restriction conditions (CT = control; $n=9$ and WR = water restricted; $n=9$ ).

\begin{tabular}{|c|c|c|c|c|}
\hline & \multicolumn{2}{|c|}{ CT } & \multicolumn{2}{|c|}{ WR } \\
\hline & Mean & LSM & Mean & LSM \\
\hline Heart (g) & $0.23 \pm 0.011$ & $0.19 \pm 0.01^{\star}$ & $0.20 \pm 0.01$ & $0.23 \pm 0.01$ \\
\hline Liver (g) & $0.57 \pm 0.041$ & $0.49 \pm 0.04$ & $0.41 \pm 0,02$ & $0.49 \pm 0.04$ \\
\hline Intestine (g) & $\begin{array}{l}0.46 \pm 0.03 \\
(71.28 \%)\end{array}$ & $0.39 \pm 0.02$ & $\begin{array}{l}0.34 \pm 0,02 \\
(72.56 \%)\end{array}$ & $0.40 \pm 0.03$ \\
\hline Kidney (g) & $0.20 \pm 0.01$ & $0.18 \pm 0.01^{*}$ & $0.21 \pm 001$ & $0.22 \pm 0.01$ \\
\hline Pectoral (g) & $\begin{array}{l}0.85 \pm 0.12 \\
(76.77 \%)\end{array}$ & $0.66 \pm 0.11$ & $\begin{array}{l}0.63 \pm 0.03 \\
(75.50 \%)\end{array}$ & $0.82 \pm 0.11$ \\
\hline
\end{tabular}

Asterisk denotes significant differences in LSM between experimental groups after an ANCOVA (see Supplementary Table 1B for details). The mean percentage of water for intestine and pectoral muscle are provided in parentheses.

decreased by $6.4 \%$ (Figure 1). The masses of internal organs were all correlated with final body mass (see Supplementary Table 1B) and the ANCOVAs showed that when body mass was accounted for the masses of heart $\left[F_{(1,15)}=5.67 ; p=0.030\right]$ and kidneys $\left[F_{(1,15)}=9.621 ; p=0.008\right]$ were influenced by water restriction, with the WR group having larger organs than the CT group (Table 1 and Supplementary Table 1B).

\section{Quantitative Magnetic Resonance Measurements}

At the end of the second acclimation experiment, birds in the WR group had $\sim 12 \%$ lower body mass $\left[F_{(1,9)}=10.79 ; p<0.001\right]$, $10 \%$ lower lean mass $\left[F_{(1,9)}=11.72 ; p=0.008\right]$, and $11 \%$ lower total water content $\left[F_{(1,9)}=13.97 ; p=0.005\right]$ in comparison to the CT group (Table 2). No significant differences were found in fat mass $\left[F_{(1,9)}=0.07 ; p=0.79\right]$ and free water content among treatments $\left[F_{(1,9)}=2.04 ; p=0.18\right]$. The calculated hydration index values were $2 \%$ higher in the CT versus WR group [ $F$ $(1,9)=18.59 ; p=0.002]$. Finally, we found a strong and positive relationship between total body water and lean mass when all individuals were pooled $(r=0.98 ; p<0.001)$.

\section{Physiological Responses}

Concentration of body fluids were not affected by body mass (Supplementary Table 1C). Blood plasma osmolality did not significantly differ between the experimental treatments $[F$ $(1,14)=1.70 ; p=0.21$ Figure 2], however, at the end of the 2 -week acclimation period we observed a significant increase of $\sim 57.0 \%$ $\left[F_{(1,14)}=123.2 ; p=0.001\right]$ in urine osmolality in the dehydrated relative to the hydrated treatment (Figure 2).

Sparrows in WR group had $\sim 12 \%$ lower whole-organism TEWL in comparison to birds in the CT group $\left[F_{(1,16)}=5.42\right.$, $p=0.033$ ], however, there was no difference in whole-organism BMR between experimental treatments $\left[F_{(1,16)}=1.85, p=0.192\right.$; Table 2]. Both BMR and TEWL were significantly correlated with body mass $\left(r^{2}=0.39 ; p=0.005, r^{2}=0.282 ; p=0.023\right.$ for BMR and TEWL, respectively, Figure 3) although, the GLM revealed that only BMR was significantly correlated with body mass (Supplementary Table 1A). GLM analyses showed that the mass-adjusted BMR (least square means, LSM) of the WR group was $\sim 12 \%$ higher on average than the BMR of the CT group [ $F$ $(1,15)=4.84 ; p=0.044$, Table 3].

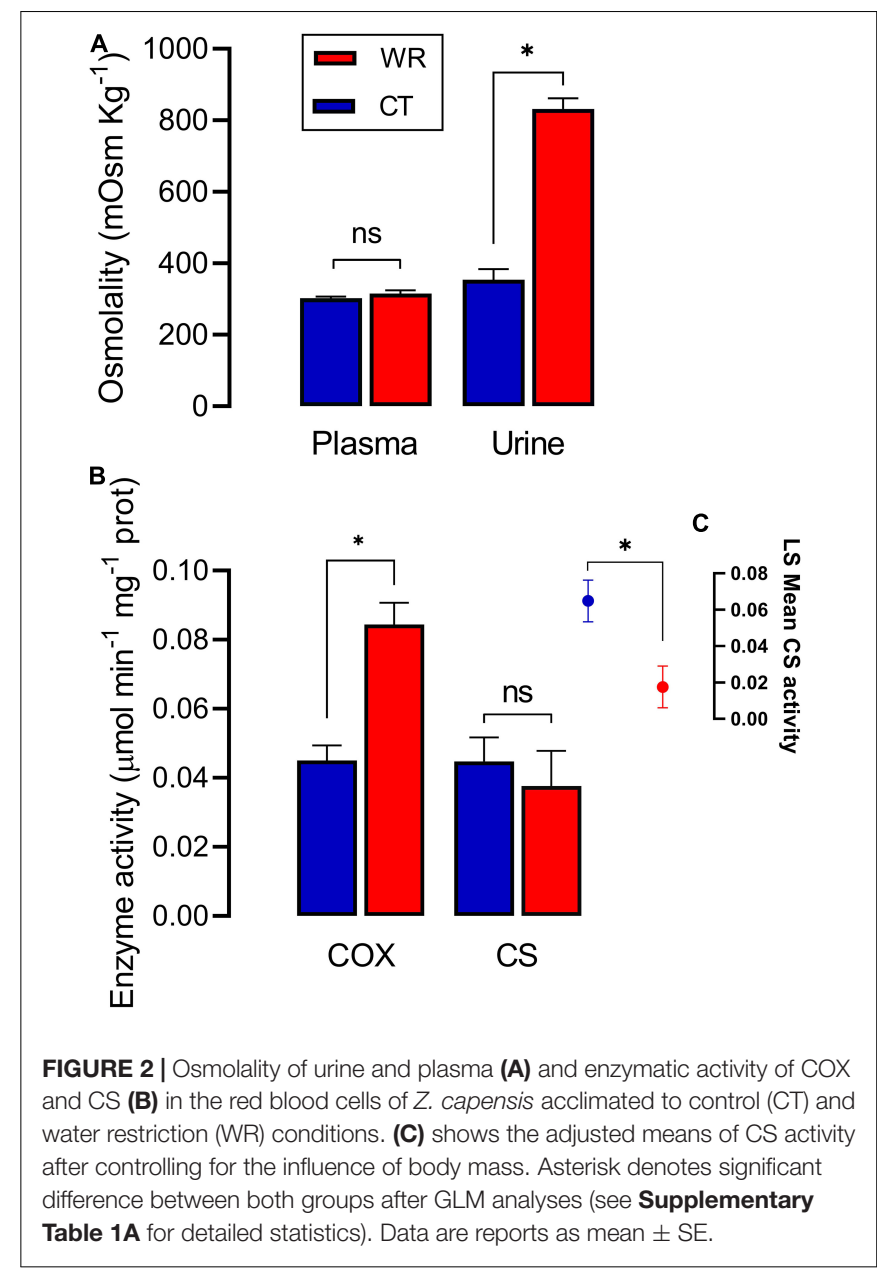


TABLE 2 | Mean ( \pm SE) of body composition in Z. capensis acclimated to water restriction (WR) and control (CT) conditions for 15 days.

\begin{tabular}{|c|c|c|c|c|c|c|}
\hline & Body mass (g) & Fat (g) & Lean (g) & Free $\mathrm{H}_{2} \mathrm{O}(\mathrm{g})$ & Total $\mathrm{H}_{2} \mathrm{O}(\mathrm{g})$ & Hydration index \\
\hline $\mathrm{CT}$ & $20.53 \pm 0.49^{\star}$ & $0.12 \pm 0.08$ & $16.24 \pm 0.31^{*}$ & $0.43 \pm 0.032$ & $14.35 \pm 0.28$ * & $0.859 \pm 0.003$ \\
\hline WR & $18.12 \pm 0.54$ & $0.15 \pm 0.09$ & $14.66 \pm 0.34$ & $0.36 \pm 0.036$ & $12.79 \pm 0.31$ & $0.842 \pm 0.003$ \\
\hline
\end{tabular}

Asterisks denote significant differences between mean values of experimental groups after ANOVA.

After correcting for body mass, the activity of CS in erythrocytes was significantly higher in the CT than in the WR treatment $\left[F_{(1,15)}=5.49, p=0.030\right.$; Figure 2], and the average activity of the metabolic enzyme cytochrome-c-oxidase was significantly higher in the WR than in the CT treatment $\left[F_{(1,16)}=26.08, p<0.001\right.$, Figures 2, 3 and Supplementary Table 1A]. The GLM analysis on pooled data revealed that whole animal BMR was affected by body mass $\left[F_{(1,16)}=37.70\right.$, $p<0.0001]$, COX activity $\left[F_{(1,16)}=17.93, p=0.001\right]$, but not by CS activity $\left[F_{(1,16)}=0.10, p=0.75\right]$. We also observed a significant and positive correlation between the residuals of the relationships between body mass versus BMR or COX activity $\left(y=279.0 \mathrm{x}+0.00 ; r^{2}=0.560, p<0.001 ;\right.$ Figure 4).

\section{Oxidative Status}

Concentrations of markers of oxidative status were significantly different among tissues (Figures 5, 6), but there was no effect of body mass on these parameters except for glutathione concentrations in pectoral muscle (see Supplementary Table 1D). Lipid peroxidation was higher in the pectoral muscle of WR birds $\left[F_{(1,16)}=6.98 ; p=0.018\right.$, Figure 5A], while heart $\left[F_{(1,16)}=2.44 ; p=0.138\right]$, liver $\left[F_{(1,16)}=2.69\right.$; $p=0.127]$, plasma $\left[F_{(1,16)}=0.02 ; p=0.870\right]$, and erythrocytes $[F$ $(1,16)=1.73 ; p=0.207]$ showed no significant differences between experimental groups. No significant differences in hydrogen peroxide concentration were observed between treatments in pectoral muscle $\left[F_{(1,16)}=0.61\right.$; $\left.p=0.446\right]$, heart $\left[F_{(1,16)}=0.69\right.$; $p=0.419]$, liver $\left[F_{(1,16)}=1.03 ; p=0.330\right]$, or blood plasma $[F$ $(1,16)=0.31 ; p=0.586]$ (Figure 5B). TAC did not differ between treatments for pectoral muscle $\left[F_{(1,16)}=1.31 ; p=0.259\right]$, heart $\left[F_{(1,16)}=2.43 ; p=0.139\right]$, or blood plasma $\left[F_{(1,16)}=0.24\right.$; $p=0.630$; Figure 5C]. Pectoral muscle of WR birds had lower glutathione concentrations for both the reduced GSH and oxidized GSSH forms in comparison to the hydrated group (see Supplementary Table 1D), but this difference disappeared when body mass was accounted for $\left[F_{(1,15)}=0.17 ; p=0.685\right.$ and $F$ $(1,16)=0.34 ; p=0.568$, respectively]. GSH/GSSG ratio in pectoral showed no between treatments $\left[F_{(1,16)}=1.14 ; p=0.302\right]$. GSH $\left[F_{(1,16)}=3.52 ; p=0.080\right]$, GSSG $\left[F_{(1,16)}=0.93 ; p=0.350\right]$, and GSH/GSSG $\left[F_{(1,16)}=2.43 ; p=0.138\right]$ in liver did not differ between treatments (Figure 6).

\section{DISCUSSION}

\section{Energy and Osmoregulatory Adjustments}

Some bird species respond to (fresh)water limitation by increasing their rates of energy expenditure (including
BMR), a response that is commonly associated with increased osmoregulatory demands in birds inhabiting arid environments or that regularly drink salty water (Gutiérrez et al., 2011; Sabat et al., 2017). An alternative perspective is that such responses could be adaptive, considering that increases in metabolic rate may result in increased MWP, which reduces the need for water conservation and/or reliance on (pre-formed) drinking/food water. To what extent an increase in metabolic rate is explained by the need to produce greater amounts of metabolic water is an open question. Recent research that quantified water budgets in field and laboratory animals have suggested that both extrinsic (e.g., acclimation temperature) and intrinsic (body mass, torpor) affect rates of energy expenditure, which can in turn increase the proportion of metabolic water in the total body water pool (Cooper et al., 2019; Whiteman et al., 2019). Interestingly, seabirds that routinely drink seawater appear to increase their metabolic rate by a greater amount than is required to meet the thermodynamically derived estimates of osmotic work. Such excess increases in metabolic rate could be an adaptive mechanism for increased MWP to maintain water balance (Peña-Villalobos et al., 2013; Sabat et al., 2017).

Dehydration and the associated decrease in body mass (Figure 1) is correlated with higher mass-adjusted BMR and MWP in sparrows (Table 3). When coupled with reduced TEWL as body mass decreased (Figure 3B), higher MWP likely minimized dehydration in the WR treatment. The observed body mass loss and increases in mass-adjusted BMR may suggests that $Z$. capensis may simultaneously increase protein catabolism and production of metabolic water through oxidation (Gerson and Guglielmo, 2011). This may minimize the level of tissue dehydration as most tissues had similar masses regardless of hydration treatment (Table 1). While these adjustments could be adaptive and lead to greater resilience to limited water availability, this strategy is costly in terms of mass loss. In birds, catabolism of protein tissue delivers a higher net amount of preformed water per gram in comparison to catabolism of lipids (Gerson and Guglielmo, 2011), so the ability to preferentially use protein over lipid reserves may help maintain water balance at the expense of losing muscle and therefore lean body mass. Wholeanimal metabolic rates were similar between experimental treatments (Table 3) despite significant decreases in body mass observed in the WR group. It is possible that if the observed decrease in body mass was mostly due to water loss rather than to loss of lean mass, then we are over-estimating massadjusted BMR because body water does not directly contribute to metabolism. Unfortunately, we were not able to measure changes in body composition before and after the initial experiment, but the second acclimation trial allowed us to assess whether mass loss in WR treatment was driven by changes in lean mass, 


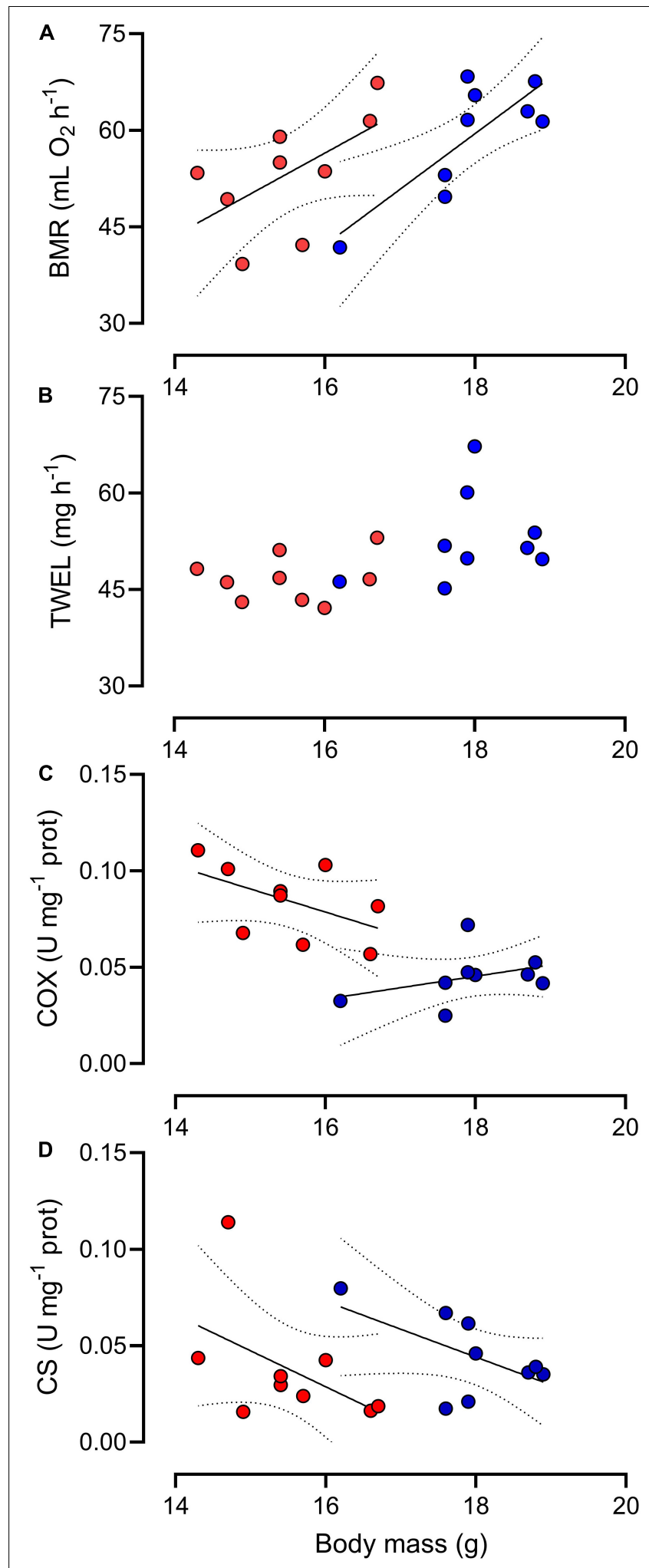

FIGURE 3 | Basal metabolic rate (A), total evaporative water loss (B), cytochrome c-oxidase (C), and citrate synthase (D) activities in erythrocytes as a function of body mass in Z. capensis individuals acclimated to control (blue symbol) and water restriction (red symbol) conditions. Lines indicate significant differences between hydrated and dehydrated groups. fat, or water content. The minimal (2\%) difference in hydration index we observed between treatments (ca 0.85, Table 2) coupled with the observation that changes in total water content were associated with a decrease in lean mass, suggests that the observed decrease in total water was likely the consequence of lean mass loss (Guglielmo et al., 2011). Indeed, our results suggest that WR birds increased protein catabolism because their lean mass decreased by $\sim 10 \%$, which is consistent with the overall decrease in body mass of $\sim 12 \%$. Thus, while the lower water content in bird tissues may partially explain the higher mass-adjusted BMR in WR birds, most of the change in BMR is likely driven by increases in the specific metabolic activity of internal organs (heart and kidneys) and muscle tissue. Because protein was differentially catabolized between the two experimental groups but whole-animal BMR did not vary, observed changes in massspecific BMR suggest that the metabolic activity of specific tissues are quite plastic (see below). Nonetheless, we caution that BMR and body condition was measured in different individuals, so this hypotheses is preliminary and required further study.

Variation in avian metabolic rate is usually associated with changes in specific energy expenditure of internal organs, which in turn is influenced by both organ mass and mass-specific metabolism of tissues controlled by mitochondrial density and/or enzyme activity (Vézina and Williams, 2005; Sabat et al., 2019). Results for $Z$. capensis support the idea that dehydration reduces body size which leads to an increase in the relative size of the kidneys and heart (Table 1). It appears that an increase in osmoregulatory demand associated with the need to concentrate urine in some passerine species that consume protein-rich and salty resources elicit the same response in kidney and heart morphology (e.g., Sabat et al., 2004a,b; Peña-Villalobos et al., 2013). This is interesting as it has been reported that these internal organs have disproportionately high mass-specific metabolic rates and that the variation in mass-independent metabolism reflects the relative size of this metabolically active machinery (Daan et al., 1990). Unfortunately, we only measured the mass-specific metabolic rate of blood, which was significantly higher in the WR than CT group. Even though blood volume represents $\sim 8-10 \%$ of the total volume in birds (Sturkie and Griminger, 1986), it is unknown what proportional contribution blood cells make to the total metabolic rate. Nord et al. (2021) reported that coal tits (Periparus ater) and great tits (Parus major) increased their mitochondrial respiration rates and CS activity of RBCs in winter, which may be a response to changes in metabolic demands between seasons. In the following sections, we offer alternative explanations for the observed increases in mass-adjusted BMR and COX activity in RBCs and why it could be associated to the costs of osmotic stress.

\section{Changes in Erythrocyte Metabolic Activity}

Perhaps the most remarkable result to emerge from our study is that birds exhibited an increase in COX activity in erythrocytes when exposed to chronic dehydration compared to those with ad lib access to water. Furthermore, variation in erythrocyte $\mathrm{COX}$ activity was associated with variation in levels of energy 
TABLE 3 | Mean ( \pm SE) and mass-adjusted (least square means, LSM) basal metabolic rate (BMR, $\mathrm{mLO}_{2} \mathrm{~h}^{-1}$ ) and total evaporative water loss (TEWL, mg $\mathrm{H}_{2} \mathrm{O} \mathrm{h}^{-1}$ ), estimated metabolic water production (MWP, $\mathrm{mg} \mathrm{H}_{2} \mathrm{O} \mathrm{h}^{-1}$ ), the ratio MWP/TEWL and body mass (Mb) of $Z$. capensis acclimated to water restriction (WR) and control (CT) conditions

\begin{tabular}{|c|c|c|c|c|c|c|c|}
\hline & \multicolumn{2}{|c|}{ BMR } & \multicolumn{2}{|c|}{ TEWL } & \multirow{2}{*}{$\begin{array}{l}\text { MWP } \\
\text { Mean }\end{array}$} & \multirow{2}{*}{$\begin{array}{l}\text { MPW/TEWL } \\
\text { Mean }\end{array}$} & \multirow{2}{*}{$\begin{array}{l}\text { mb (g) } \\
\text { Mean }\end{array}$} \\
\hline & Mean & LSM & Mean & LSM & & & \\
\hline CT & $59.1 \pm 3.0$ & $49.8 \pm 3.3^{*}$ & $52.82 \pm 2.2^{*}$ & $50.9 \pm 2.2$ & $33.5 \pm 5.0$ & $0.63 \pm 0.07$ & $17.9 \pm 2.7^{\star}$ \\
\hline WR & $53.3 \pm 2.9$ & $62.6 \pm 3.3$ & $46.73 \pm 1.2$ & $48.61 \pm 2.2$ & $30.2 \pm 5.1$ & $0.64 \pm 0.08$ & $15.2 \pm 2.7$ \\
\hline
\end{tabular}

Asterisk denote significant differences between experimental groups. See text for statistics.

expenditure. One of the unique characteristics of birds and often overlooked by ecological and evolutionary physiologists is the presence of nucleated RBCs with functional mitochondria. This key feature has recently caught the attention of physiologists and the existence of intra and interspecific variation in its function has been observed in a few species (Stier et al., 2013, 2015, 2017; Nord et al., 2021). Decades ago, some suggested that ATP production in erythrocytes is involved in the maintenance of ion balance $(\mathrm{Na}$ and $\mathrm{K}$ ) between erythrocytes and plasma (Hunter and Hunter, 1957). Others proposed that the presence of nucleated RBCs with functional mitochondria could be associated with regulatory mechanisms of cell volume using ion transport proteins (e.g., $\mathrm{Na}^{+} / \mathrm{H}^{+}, \mathrm{Na}^{+}-\mathrm{K}^{+}-2 \mathrm{Cl}^{-}$cotransport and $\mathrm{Na}^{+}$channels), which are mediated by ATP-dependent membrane proteins (e.g., NHEs, KCC, and NKCC; Hoffmann et al., 2009). However, our results for $Z$. capensis do not necessarily support the hypothesis that the increase in mitochondrial oxidative activity in the erythrocyte is exclusively driven by the regulation of cell volume. Plasma osmolality was similar in WR and CT birds, and by extension the osmotic pressure experienced by erythrocytes was probably similar between treatments, which also suggests that Zonotrichia was able to maintain hydric homeostasis in our experiment.

Although the lack of published data precludes a clear explanation for the observed variation in erythrocyte COX and CS activities, it is interesting that after removing the effect of body mass, only COX activity correlates positively with BMR. This

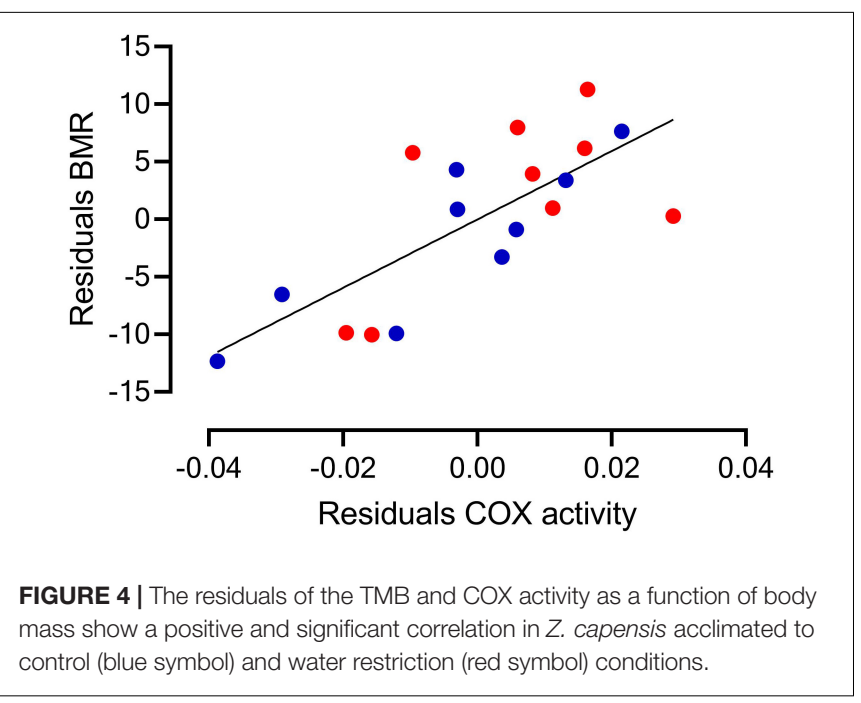

finding is consistent with those recently reported by Gutiérrez et al. (2019) for the Hudsonian godwit (Limosa haemastica), who suggested that the rate of energy expenditure in godwits could be driven by metabolic demands of organs and tissues, including blood. While our results show somewhat contradictory patterns of COX and CS expression in RBCs, comparable results were also observed in Hudsonian godwits collected in winter (Gutiérrez

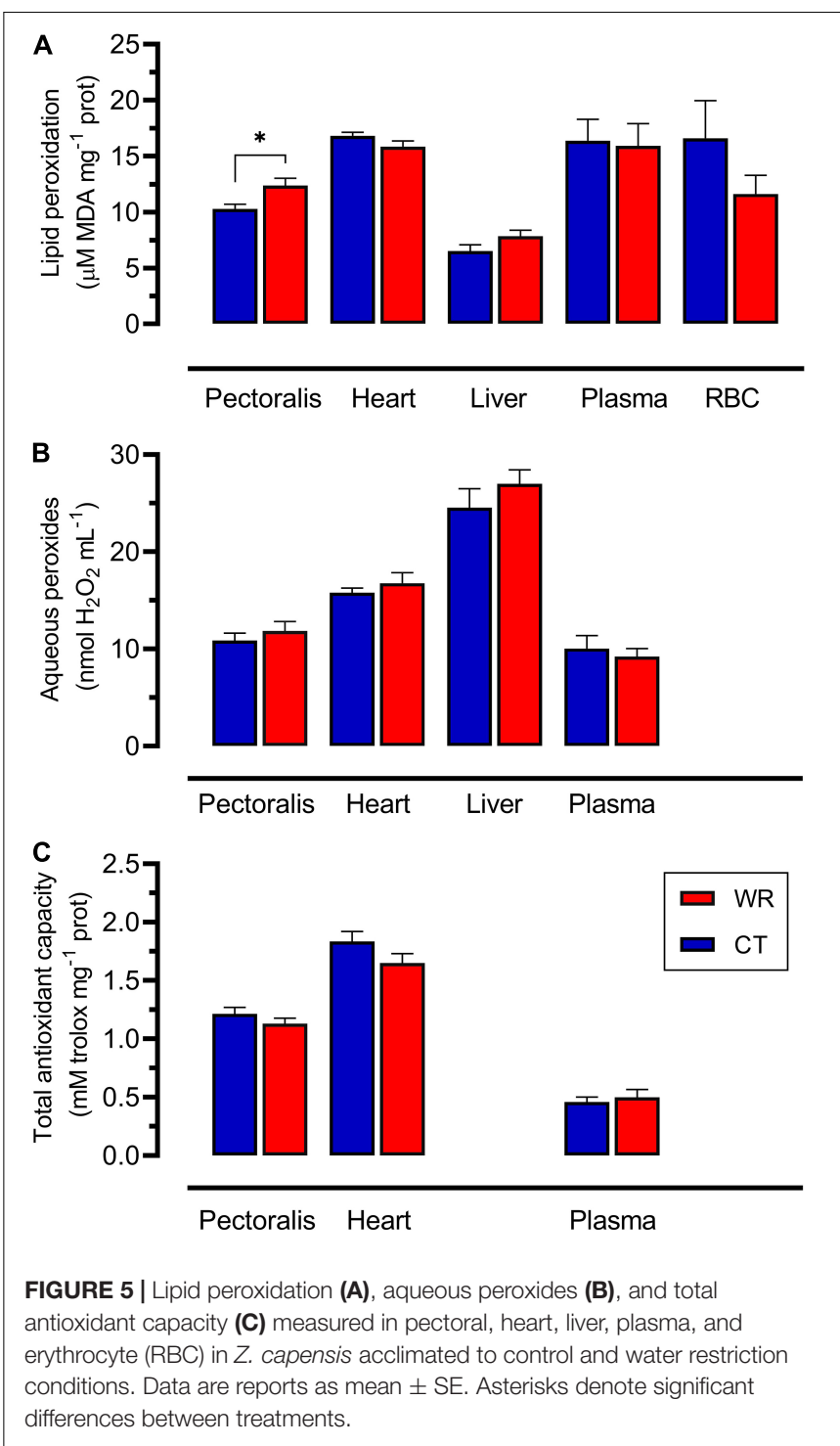




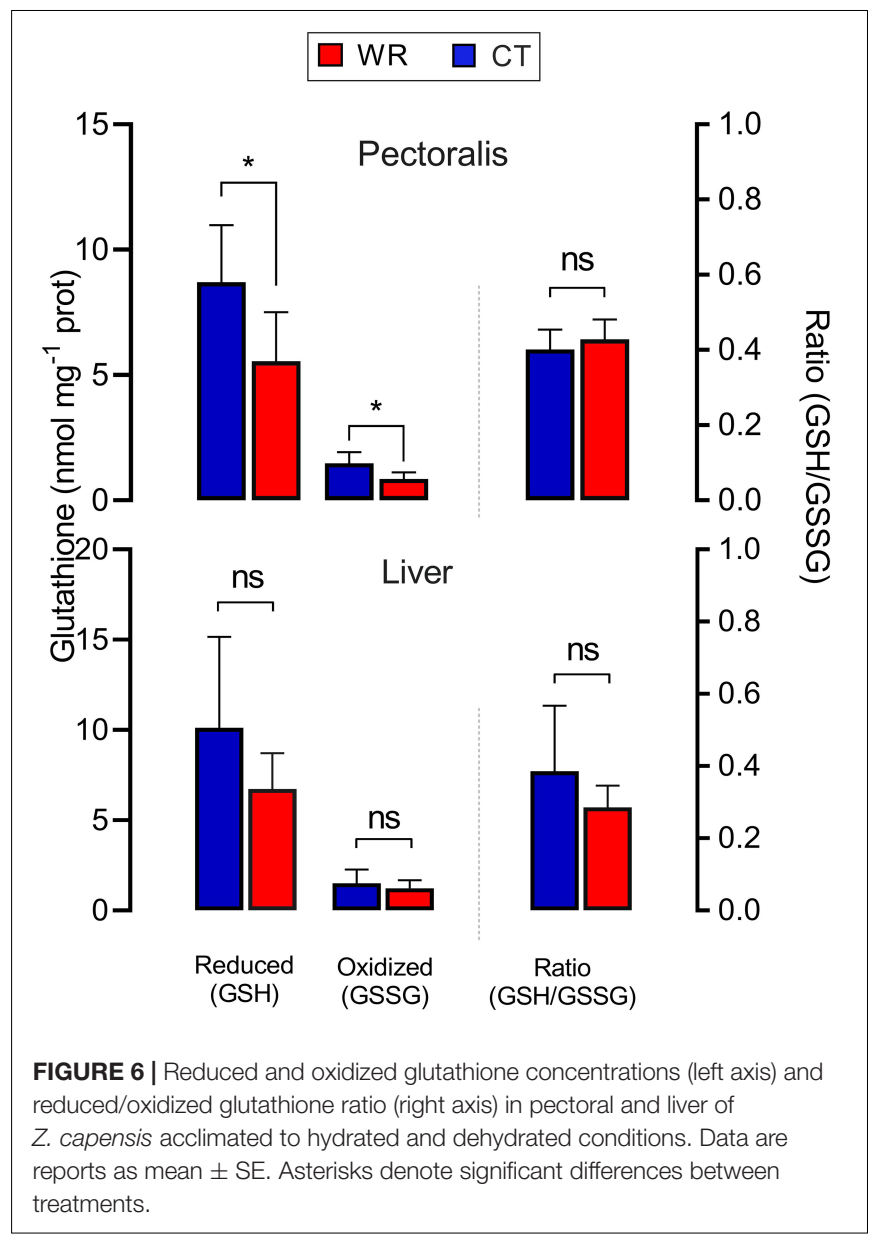

et al., 2019).As these authors pointed out there could be other physiological processes, such as tissue growth and repair, that differentially modulate the expression of CS and COX in RBCs of birds (Velando et al., 2019).

For Z. capensis, at least two non-exclusive alternatives may explain the relationship found between mass-adjusted BMR and erythrocyte COX activity. First, the increase in catabolic capacity in erythrocytes could be a response to vasoconstriction caused by water restriction. It is well known that dehydration causes vasoconstriction of blood capillaries, which decreases the delivery of oxygen to tissues (Kreimeier, 2000). In addition, erythrocytes can detect oxygen tension via microcirculation, regulating the vascular tone of capillaries in specific tissues (Jensen, 2009). In the case of hypoxia caused by vasoconstriction induced to dehydration, erythrocytes could increase the release of vasodilator compounds (e.g., NO, ATP), locally promoting an increase in blood perfusion of tissues that require oxygen (Ellsworth et al., 1995) and thus increasing its oxidative activity. Second, it is likely that changes in metabolic activity in the blood could be driven by increased tissue metabolism. Nutritional sensors, or proteins that respond to fluctuations in nutrients, such as Nicotinamide phosphoribosyltransferase, Sirtuins (silent information regulator), and target of rapamycin complex are likely influenced by the energy status of the organism. When faced with high oxygen requirements, animals respond by increasing nutrient use by tissues that have higher mass-specific metabolic rates such as the kidney (Gaur et al., 2017; Lee and Yang, 2017), which likely influences other tissues. Thus, the observed relationship between BMR and COX in RBCs could reflect a synergistic response to maintain vascular and respiratory homeostasis, either because the blood cells contribute to blood flow regulating vascular tone, and/or that they are influenced by the same regulatory pathways that reflect the requirements of other energy demanding tissues (e.g., liver). Malkoc et al. (2021) reported that oxygen consumption at the cellular level in RBCs of great tits (Parus major) is directly related to oxygen consumption at the organismal level. This pattern was observed only when birds did not display signs of stress as inferred from plasma corticosterone concentrations, indicating that work examining the effects of stress on metabolic rate at both the mitochondrial and organismal level warrants further exploration.

\section{Oxidative Status}

Sparrows in the WR group had higher levels of lipid peroxidation as measured by MDA concentrations in pectoral muscle, a sign of higher oxidative damage relative to birds with ad lib access to water. These finding are supported by our previous work showing a $400 \%$ increase in MDA concentration in Z. capensis fed saltwater (Sabat et al., 2017). Observed differences in oxidative damage of pectoral muscle between treatments in this experiment suggest signs of oxidative stress in $Z$. capensis exposed to water restriction, despite pro-oxidants (peroxides) nor antioxidant capacity (TAC) not varying between treatments. Membrane damage in pectoral muscle of dehydrated birds could be explained in part by the observed increase in mass-specific $\mathrm{BMR}$, which might promote the production of free radicals or ROS. Studies have reported contrasting results regarding the functional association between metabolic rate and ROS production under controlled conditions both in ectotherms and endotherms (Hermes-Lima and Storey, 1998; Brzęk et al., 2014; Salin et al., 2015; Zhang and Wong, 2021). Unfortunately, few studies have assessed the effects of dehydration and stress (including oxidative damage) in birds, although a recent publication reported an association between dehydration and increased corticosterone concentrations in free-ranging house sparrows (Passer domesticus; Brischoux et al., 2020). While it is known that corticosterone and other glucocorticoids disturb cellular oxidative homeostasis (Costantini et al., 2011; Queisser et al., 2011), it is unknown whether dehydration causes oxidative damage in birds. Further experimental data are required to accurately assess how dehydration affects oxidative status in birds and which intrinsic (e.g., biochemical) and/or extrinsic (e.g., ecological) mechanisms underpin their response.

\section{CONCLUSION}

We found that captive $Z$. capensis responds to water restriction by losing mass and increasing their mass-specific maintenance metabolism, a pattern that suggests that the simultaneous 
increase in protein catabolism and production of metabolic water through oxidation may help maintain water balance. A noteworthy result is that birds exhibited an increase in COX activity in erythrocytes in response to chronic water restriction, and that variation in COX activity was positively correlated with mass-adjusted BMR. Finally, we found a moderate effect of water restriction on membrane damage of skeletal muscle, which confirms that hydration state and changes in osmotic conditions may cause oxidative damage. Further investigation of how birds use physiological mechanisms to maintain water balance is needed to better understand how they will respond to rapidly shifting environmental conditions that will likely generate increases in ambient temperature but decreases in water availability in aridland ecosystems throughout the world.

\section{DATA AVAILABILITY STATEMENT}

The raw data supporting the conclusions of this article will be made available by the authors, without undue reservation.

\section{ETHICS STATEMENT}

The animal study was reviewed and approved by the Institutional Animal Care Committee of the University of Chile.

\section{REFERENCES}

Albright, T. P., Mutiibwa, D., Gerson, A. R., Smith, E. K., Talbot, W. A., O’Neill, J. J., et al. (2017). Mapping evaporative water loss in desert passerines reveals an expanding threat of lethal dehydration. Proc. Natl. Acad. Sci. U S A. 114, 2283-2288. doi: 10.1073/pnas.1613625114

Bradford, M. M. (1976). A rapid and sensitive method for the quantitation of microgram quantities of protein utilizing the principle of protein-dye binding. Anal. Biochem. 72, 248-254. doi: 10.1016/0003-2697(76)90527-3

Brischoux, F., Beaugeard, E., Mohring, B., Parenteau, C., and Angelier, F. (2020). Short-term dehydration influences baseline but not stress-induced corticosterone levels in the house sparrow (Passer domesticus). J. Exp. Biol. 223:jeb216424. doi: 10.1242/jeb.216424

Brzęk, P., Książek, A., Ołdakowski, Ł, and Konarzewski, M. (2014). High basal metabolic rate does not elevate oxidative stress during reproduction in laboratory mice. J. Exp. Biol. 217, 1504-1509. doi: 10.1242/jeb.100073

Cade, T. J., Tobin, C. A., and Gold, A. (1965). Water economy and metabolism of two estrildine finches. Physiol. Zool. 38, 9-33. doi: 10.1086/physzool.38.1. 30152342

Cohen, A. A., Hau, M., and Wikelski, M. (2008). Stress, metabolism, and antioxidants in two wild passerine bird species. Physiol. Biochem. Zool. 81, 463-472. doi.org/10.1086/589548

Commoner, B., Townsend, J., and Pake, G. E. (1954). Free radicals in biological materials. Nature 174, 689-691. doi: 10.1038/174689a0

Cooper, C. E., Withers, P. C., Hurley, L. L., and Griffith, S. C. (2019). The field metabolic rate, water turnover, and feeding and drinking behavior of a small avian desert granivore during a summer heatwave. Front. Physiol. 10:1405. doi: 10.3389/fphys.2019.01405

Costantini, D. (2014). Oxidative Stress and Hormesis in Evolutionary Ecology and Physiology: a Marriage between Mechanistic and Evolutionary Approaches. Berlin: Springer-Verlag. doi: 10.1007/978-3-642-54663-1

Costantini, D., Marasco, V., and Møller, A. P. (2011). A meta-analysis of glucocorticoids as modulators of oxidative stress in vertebrates. J. Comp. Physiol. B. 181, 447-456. doi: 10.1007/s00360-011-0566-2

\section{AUTHOR CONTRIBUTIONS}

PS, SN, FB, and RN designed research. LN, IP-V, CC-R, and JS-H performed research. LN and PS analyzed data. PS, SN, FB, RN, JS-H, LN, and IP-V wrote the manuscript. All authors contributed to the article and approved the submitted version.

\section{FUNDING}

This work was funded by ANID/FONDECYT Regular $\mathrm{N}^{\circ}$ 1200386, ANID PIA/BASAL FB0002, and FONDEQUIP grant $\mathrm{N}^{\circ}$ EQM180055.

\section{ACKNOWLEDGMENTS}

We thank to Felipe Alvarez, Carlos Mejias, Andrés Sazo, and Natalia Ramirez its invaluable laboratory and fieldwork assistance.

\section{SUPPLEMENTARY MATERIAL}

The Supplementary Material for this article can be found online at: https://www.frontiersin.org/articles/10.3389/fevo.2021. 767280/full\#supplementary-material

Costantini, D., Rowe, M., Butler, M. W., and McGraw, K. J. (2010). From molecules to living systems: historical and contemporary issues in oxidative stress and antioxidant ecology. Funct. Ecol. 24, 950-959. doi: 10.1111/j.1365-2435.2010. 01746.x

Daan, S., Masman, D., and Groenewold, A. (1990). Avian basal metabolic rates: their association with body composition and energy expenditure in nature. Am. J. Phys. Regul. Integr. Comp. Phys. 259, R333-R340. doi: 10.1152/ajpregu.1990. 259.2.R333

Eastick, D. L., Edwards, A. M., Griffiths, S. R., Spencer, S. J., and Robert, K. A. (2020). Validation of quantitative magnetic resonance as a non-invasive measure of body composition in an Australian microbat. Aust. Mammal. 43, 196-202. doi: 10.1071/AM19060

Ellsworth, M. L., Forrester, T., Ellis, C. G., and Dietrich, H. H. (1995). The erythrocyte as a regulator of vascular tone. Am. J. Physiol. Heart Circ. Physiol. 269, H2155-H2161. doi: 10.1152/ajpheart.1995.269.6.H2155

Gardner, J. L., Peters, A., Kearney, M. R., Joseph, L., and Heinsohn, R. (2011). Declining body size: a third universal response to warming? Trends Ecol. Evol. 26, 285-291. doi: 10.1016/j.tree.2011.03.005

Gaur, U., Tu, J., Li, D., Gao, Y., Lian, T., Sun, B., et al. (2017). Molecular evolutionary patterns of NAD+/Sirtuin aging signaling pathway across taxa. PLoS One 12:e182306. doi: 10.1371/journal.pone.0182306

Gerson, A. R., and Guglielmo, C. G. (2011). House sparrows (Passer domesticus) increase protein catabolism in response to water restriction. Am. J. Physiol. Regul. Integr. Comp. Physiol. 300, R925-R930. doi: 10.1152/ajpregu.00701. 2010

Guglielmo, C. G., McGuire, L. P., Gerson, A. R., and Seewagen, C. L. (2011). Simple, rapid, and non-invasive measurement of fat, lean, and total water masses of live birds using quantitative magnetic resonance. J. Ornithol. 152:75. doi: 10.1007/s10336-011-0724-z

Gutiérrez, J. S., Masero, J. A., Abad-Gómez, J. M., Villegas, A., and SánchezGuzmán, J. M. (2011). Understanding the energetic costs of living in saline environments: effects of salinity on basal metabolic rate, body mass and daily energy consumption of a long-distance migratory shorebird. J. Exp. Biol. 214, 829-835. doi: 10.1242/jeb.048223 
Gutiérrez, J. S., Sabat, P., Castañeda, L. E., Contreras, C., Navarrete, L., PeñaVillalobos, I., et al. (2019). Oxidative status and metabolic profile in a long-lived bird preparing for extreme endurance migration. Sci. Rep. 9:17616. doi: 10.1038/ s41598-019-54057-6

Hermes-Lima, M., and Storey, K. B. (1998). Role of antioxidant defenses in the tolerance of severe dehydration by anurans. the case of the leopard frog Rana pipiens. Mol. Cell. Biochem. 189, 79-89. doi: 10.1023/A:100686820 8476

Hoffmann, E. K., Lambert, I. H., and Pedersen, S. F. (2009). Physiology of cell volume regulation in vertebrates. Physiol. Rev. 89, 193-277. doi: 10.1152/ physrev.00037.2007

Hunter, A. S., and Hunter, F. (1957). A comparative study of erythrocyte metabolism. J. Cell. Physiol. 49, 479-502. doi: 10.1002/jcp.1030490307

Iknayan, K. J., and Beissinger, S. R. (2018). Collapse of a desert bird community over the past century driven by climate change. PNAS 115, 8597-8602. doi: $10.1073 /$ pnas. 1805123115

Jacobs, P. J., Oosthuizen, M. K., Mitchell, C., Blount, J. D., and Bennett, N. C. (2020). Heat and dehydration induced oxidative damage and antioxidant defenses following incubator heat stress and a simulated heat wave in wild caught four-striped field mice Rhabdomys dilectus. PLoS One 15:e0242279. doi: 10.1371/journal.pone.0242279

Jensen, F. B. (2009). The dual roles of red blood cells in tissue oxygen delivery: oxygen carriers and regulators of local blood flow. J. Exp. Biol. 212, 3387-3393. doi: 10.1242/jeb.023697

Kelsey, N. A., and Bairlein, F. (2019). Migratory body mass increase in Northern Wheatears (Oenanthe oenanthe) is the accumulation of fat as proven by quantitative magnetic resonance. J. Ornithol. 160, 389-397. doi: 10.1007/ s10336-018-1621-5

Khaliq, I., Hof, C., Prinzinger, R., Böhning-Gaese, K., and Pfenninger, M. (2014). Global variation in thermal tolerances and vulnerability of endotherms to climate change. Proc. R. Soc. B: Biol. Sci. 281:20141097. doi: 10.1098/rspb.2014. 1097

King, J. R., and Farner, D. S. (1961). "Energy metabolism, thermoregulation and body temperature," in Biology and Comparative Physiology of Birds, ed. A. J. Marshall (New York, NY: Academic Press).

Kraft, F. L. O., Driscoll, S. C., Buchanan, K. L., and Crino, O. L. (2019). Developmental stress reduces body condition across avian life-history stages: a comparison of quantitative magnetic resonance data and condition indices. Gen. Comp. Endocrinol. 272, 33-41. doi: 10.1016/j.ygcen.2018.1 1.008

Kreimeier, U. (2000). Pathophysiology of fluid imbalance. J. Crit. Care 4, 1-5. doi: $10.1186 /$ cc968

Lee, H. J., and Yang, S. J. (2017). Aging-related correlation between serum sirtuin 1 activities and basal metabolic rate in women, but not in men. Clin. Nutr. Res. 6, 18-26. doi: 10.7762/cnr.2017.6.1.18

Lide, D. R. (2001). CRC Handbook of Physics and Chemistry. Boca Raton, FL: CRC Press.

Maldonado, K. E., Cavieres, G., Veloso, C., Canals, M., and Sabat, P. (2009). Physiological responses in rufous-collared sparrows to thermal acclimation and seasonal acclimatization. J. Comp. Physiol. B 179, 335-343. doi: 10.1007/s00360008-0317-1

Malkoc, K., Casagrande, S., and Hau, M. (2021). Inferring whole-organism metabolic rate from red blood cells in birds. Front. Physiol. 12:691633. doi: 10.3389/fphys.2021.691633

McKechnie, A. E., and Wolf, B. O. (2010). Climate change increases the likelihood of catastrophic avian mortality events during extreme heat waves. Biol. Lett. 6, 253-256. doi: 10.1098/rsbl.2009.0702

McWhorter, T. J., del Rio, C. M., Pinshow, B., and Roxburgh, L. (2004). Renal function in Palestine sunbirds: elimination of excess water does not constrain energy intake. J. Exp. Biol. 207, 3391-3398. doi: 10.1242/jeb. 01169

Moritz, K., Lim, G. B., and Wintour, E. (1997). Developmental regulation of erythropoietin and erythropoiesis. Am. J. Physiol. Regul. Integr. Comp. Physiol. 273, R1829-R1844. doi: 10.1152/ajpregu.1997.273.6. R1829

Nord, A., Metcalfe, N. B., Page, J. L., Huxtable, A., McCafferty, D. J., and Dawson, N. J. (2021). Avian red blood cell mitochondria produce more heat in winter than in autumn. FASEB J. 35:e21490. doi: 10.1096/fj.202100107R
Peña-Villalobos, I., Nuñez-Villegas, M., Bozinovic, F., and Sabat, P. (2014). Metabolic enzymes in seasonally acclimatized and cold acclimated rufouscollared sparrow inhabiting a Chilean Mediterranean environment. Curr. Zool. 60, 338-350. doi: 10.1093/czoolo/60.3.338

Peña-Villalobos, I., Valdés-Ferranty, F., and Sabat, P. (2013). Osmoregulatory and metabolic costs of salt excretion in the Rufous-collared sparrow Zonotrichia capensis. Comp. Biochem. Physiol. - A Mol. Integr. Physiol. 164, 314-318. doi: 10.1016/j.cbpa.2012.10.027

Queisser, N., Oteiza, P. I., Stopper, H., Oli, R. G., and Schupp, N. (2011). Aldosterone induces oxidative stress, oxidative DNA damage and NF- $\kappa$ Bactivation in kidney tubule cells. Mol. Carcinog. 50, 123-135. doi: 10.1002/mc. 20710

Rahman, I., Kode, A., and Biswas, S. K. (2006). Assay for quantitative determination of glutathione and glutathione disulfide levels using enzymatic recycling method. Nat. Protoc. 1, 3159-3165. doi: 10.1038/nprot.2006.378

Ribeiro, J. P., Magalhaes, L. M., Reis, S., Lima, J. L., and Segundo, M. A. (2011). High-throughput total cupric ion reducing antioxidant capacity of biological samples determined using flow injection analysis and microplatebased methods. Anal. Sci. 27, 483-483. doi: 10.2116/analsci.27.483

Riley, J. L., Baxter-Gilbert, J. H., Guglielmo, C. G., and Litzgus, J. D. (2016). Scanning snakes to measure condition: a validation of quantitative magnetic resonance. J. Herpetol. 50, 627-632. doi: 10.1670/15-113

Sabat, P., Bozinovic, F., Contreras-Ramos, C., Nespolo, R. F., Newsome, S. D., Quirici, V., et al. (2019). The interplay between ambient temperature and salt intake affects oxidative status and immune responses in a ubiquitous Neotropical passerine, the rufous-collared sparrow. Comp. Biochem. Physiol. Mol. Integr. Physiol. 234, 50-59. doi: 10.1016/j.cbpa.2019.04.016

Sabat, P., Gonzalez-Vejares, S., and Maldonado, K. (2009). Diet and habitat aridity affect osmoregulatory physiology: an intraspecific field study along environmental gradients in the Rufous-collared sparrow. Comp. Biochem. Physiol. Mol. Integr. Physiol. 152, 322-326. doi: 10.1016/j.cbpa.2008.11.003

Sabat, P., Maldonado, K., Rivera-Hutinel, A., and Farfan, G. (2004a). Coping with salt without salt glands: osmoregulatory plasticity in three species of coastal songbirds (ovenbirds) of the genus Cinclodes (Passeriformes: Furnariidae). J. Comp. Physiol. B 174, 415-420. doi: 10.1007/s00360-004-0428-422

Sabat, P., Sepúlveda-Kattan, E., and Maldonado, K. (2004b). Physiological and biochemical responses to dietary protein in the omnivore passerine Zonotrichia capensis (Emberizidae). Comp. Biochem. Physiol. Mol. Integr. Physiol. 137, 391-396. doi: 10.1016/j.cbpb.2003.10.021

Sabat, P., and Martinez del Rio, C. (2002). Inter-and intraspecific variation in the use of marine food resources by three Cinclodes (Furnariidae, Aves) species: carbon isotopes and osmoregulatory physiology. Zoology 105, 247-256. doi: 10.1078/0944-2006-00078

Sabat, P., Narváez, C., Peña-Villalobos, I., Contreras, C., Maldonado, K., SanchezHernandez, J. C., et al. (2017). Coping with salt water habitats: metabolic and oxidative responses to salt intake in the rufous-collared sparrow. Front. Physiol. 8:654. doi: 10.3389/fphys.2017.00654

Sabat, P., Newsome, S. D., Pinochet, S., Nespolo, R., Sanchez-Hernandez, J. C., Maldonado, K., et al. (2021). Triple oxygen isotope measurements ( $\left.\Delta^{\prime} 17 \mathrm{O}\right)$ of body water reflect water intake, metabolism, and $\delta 180$ of ingested water in passerines. Front. Physiol. 12:710026. doi: 10.3389/fphys.2021.710026

Salin, K., Auer, S. K., Rudolf, A. M., Anderson, G. J., Cairns, A. G., Mullen, W., et al. (2015). Individuals with higher metabolic rates have lower levels of reactive oxygen species in vivo. Biol. Lett. 11:20150538. doi: 10.1098/rsbl.2015.0538

Schmidt-Nielsen, K. (1997). Animal Physiology: Adaptation and Environment. Cambridge: Cambridge University Press.

Smit, B., and McKechnie, A. E. (2015). Water and energy fluxes during summer in an arid-zone passerine bird. Ibis 157, 774-786. doi: 10.1111/ibi.12284

Srinivasan, S., and Avadhani, N. G. (2012). Cytochrome c oxidase dysfunction in oxidative stress. Free Radic. Biol. Med. 53, 1252-1263. doi: 10.1016/j. freeradbiomed.2012.07.021

Stier, A., Bize, P., Schull, Q., Zoll, J., Singh, F., Geny, B., et al. (2013). Avian erythrocytes have functional mitochondria, opening novel perspectives for birds as animal models in the study of ageing. Front. Zool. 10:33. doi: 10.1186/ 1742-9994-10-33

Stier, A., Reichert, S., Criscuolo, F., and Bize, P. (2015). Red blood cells open promising avenues for longitudinal studies of ageing in laboratory, non-model and wild animals. Exp. Gerontol. 71, 118-134. doi: 10.1016/j.exger.2015.09.001 
Stier, A., Romestaing, C., Schull, Q., Lefol, E., Robin, J. P., Roussel, D., et al. (2017). How to measure mitochondrial function in birds using red blood cells: a case study in the king penguin and perspectives in ecology and evolution. Methods Ecol. Evol. 8, 1172-1182. doi: 10.1111/2041-210X.12724

Sturkie, P. D., and Griminger, P. (1986). "Body fluids: blood," in Avian Physiology, ed. P. D. Sturkie (New York, NY: Springer), doi: 10.1007/978-1-4612-4862-0_5

Tapia-Monsalve, R., Newsome, S. D., Sanchez-Hernandez, J. C., Bozinovic, F., Nespolo, R., and Sabat, P. (2018). Terrestrial birds in coastal environments: metabolic rate and oxidative status varies with the use of marine resources. Oecologia 188, 65-73. doi: 10.1007/s00442-018-4181-8

Tieleman, B. I., Williams, J. B., Buschur, M. E., and Brown, C. R. (2003). Phenotypic variation of larks along an aridity gradient: are desert birds more flexible? Ecology 84, 1800-1815.

Tumminello, R. A., and Fuller-Espie, S. L. (2013). Heat stress induces ROS production and histone phosphorylation in celomocytes of Eisenia hortensis. ISJ 10, 50-57.

Velando, A., Noguera, J. C., da Silva, A., and Kim, S. Y. (2019). Redox-regulation and life-history trade-offs: scavenging mitochondrial ROS improves growth in a wild bird. Sci. Rep. 9:2203. doi: 10.1038/s41598-019-38535-5

Vézina, F., and Williams, T. (2005). Interaction between organ mass and citrate synthase activity as an indicator of tissue maximal oxidative capacity in breeding European starlings: implications for metabolic rate and organ mass relationships. Funct. Ecol. 19, 119-128.

Walsberg, G. E., and Wolf, B. O. (1995). Variation in the respirometry quotient of birds and implications for indirect calorimetry using measurements of carbon dioxide production. J. Exp. Biol. 198, 213-219. doi: 10.1242/jeb.198. 1.213

Walther, G. R., Post, E., Convey, P., Menzel, A., Parmesan, C., Beebee, T. J., et al. (2002). Ecological responses to recent climate change. Nature 416, 389-395. doi: $10.1038 / 416389$ a
Whiteman, J. P., Sharp, Z. D., Gerson, A. R., and Newsome, S. D. (2019). Relating $\triangle 17 \mathrm{O}$ values of animal body water to exogenous water inputs and metabolism. BioScience 69, 658-668. doi: 10.1093/biosci/biz055

Withers, P. C. (1977). Respiration, metabolism, and heat exchange of euthermic and torpid poorwills and hummingbirds. Physiol. Zool. 50, 43-52. doi: 10.1086/ physzool.50.1.30155714

Yom-Tov, Y. (2001). Global warming and body mass decline in Israeli passerine birds. Proc. R. Soc. B 268, 947-952. doi: 10.1098/rspb.2001.1592

Zhang, Y., and Wong, H. S. (2021). Are mitochondria the main contributor of reactive oxygen species in cells? J. Exp. Biol. 224:jeb221606. doi: 10.1242/jeb. 221606

Conflict of Interest: The authors declare that the research was conducted in the absence of any commercial or financial relationships that could be construed as a potential conflict of interest.

Publisher's Note: All claims expressed in this article are solely those of the authors and do not necessarily represent those of their affiliated organizations, or those of the publisher, the editors and the reviewers. Any product that may be evaluated in this article, or claim that may be made by its manufacturer, is not guaranteed or endorsed by the publisher.

Copyright (C) 2021 Navarrete, Bozinovic, Peña-Villalobos, Contreras-Ramos, Sanchez-Hernandez, Newsome, Nespolo and Sabat. This is an open-access article distributed under the terms of the Creative Commons Attribution License (CC BY). The use, distribution or reproduction in other forums is permitted, provided the original author(s) and the copyright owner(s) are credited and that the original publication in this journal is cited, in accordance with accepted academic practice. No use, distribution or reproduction is permitted which does not comply with these terms. 